\title{
FASES DA GERMINAÇÃO DE SEMENTES DE Annona emarginata (SCHLTDL.) H. RAINER EM DIFERENTES TEMPERATURAS ${ }^{1}$
}

\author{
PAULA NEPOMUCENO COSTA², SILVANA SALES CATARINA BUENO ${ }^{3}$, GISELA FERREIRA ${ }^{4}$
}

RESUMO- O presente trabalho foi realizado com o objetivo de identificar as fases da germinação de sementes de araticum-de-terra-fria (Annona emarginata (Schltdl.) H. Rainer) sob diferentes temperaturas. Para tanto, o trabalho foi dividido em dois experimentos: um para a determinação das fases I e II da germinação, e outro para a fase III. O delineamento experimental foi o inteiramente casualizado, com 3 tratamentos e 4 repetições de 25 sementes por parcela, em ambos os experimentos. Os tratamentos foram constituídos pelas temperaturas constantes de $25^{\circ} \mathrm{C}$ e $30^{\circ} \mathrm{C}$ e temperatura alternada de $20-30^{\circ} \mathrm{C}(8-16 \mathrm{~h}$, respectivamente), com luz constante. As variáveis analisadas foram a variação do grau de umidade ao longo do tempo (experimento 1), a porcentagem e a velocidade média de germinação (experimento 2). Os dados foram submetidos à análise de variância, as médias comparadas pelo teste Tukey, a 5\% de probabilidade e regressão polinomial. A variação do grau de umidade ao longo do tempo foi estudada através da regressão não linear monomolecular, com os parâmetros das funções comparados conforme os tratamentos, ajustados, submetidos à análise de variância e teste Tukey, a $5 \%$ de probabilidade. Observou-se que as sementes mantidas a $30^{\circ} \mathrm{C}$ apresentaram maiores valores para velocidade de aquisição de água, atingindo $27,85 \%$ de grau de umidade na mudança da fase I para a fase II. Quando as sementes foram submetidas a $25^{\circ} \mathrm{C}$, a fase I teve duração de 60 horas, atingindo $28,35 \%$ de grau de umidade e, sob $20 / 30^{\circ} \mathrm{C}$, a fase durou 72 horas, alcançando $28,33 \%$ de grau de umidade. Embora $30^{\circ} \mathrm{C}$ tenha promovido a maior velocidade de embebição, não refletiu em maior porcentagem de germinação (fase III), que foi observada nas sementes mantidas a $20 / 30^{\circ} \mathrm{C}$.

Termos para indexação: Annonaceae, araticum-de-terra-fria, embebição.

\section{GERMINATION PHASES OF Annona emarginata (SCHLTDL.) H. RAINER SEEDS UNDER DIFFERENT TEMPERATURES}

\begin{abstract}
This study was carried out to identify the germination phases of "araticum-de-terra-fria" (Annona emarginata (Schltdl.) H. Rainer) seeds under different temperatures. Thus, the work was divided into two experiments: one for evaluating phases I and II, and a second one for phase III. The experimental design was completely randomized, with three treatments and four replicates of 25 seeds per plot in both experiments. Treatments consisted of constant temperatures equal to $25^{\circ} \mathrm{C}$ and $30^{\circ} \mathrm{C}$, and alternate temperature $20-30^{\circ} \mathrm{C}(8-16 \mathrm{~h}$, respectively), under constant light. Humidity degree variation over time (experiment 1 ), and germination percentage and mean velocity (experiment 2) were assessed. Data were subjected to analysis of variance, and means were compared by the Tukey's test at 5\% significance, and polynomial regression. Humidity degree variation over time was evaluated through non-linear monomolecular regression; the parameters of functions were compared according to treatments, then fit and subjected to analysis of variance and Tukey's test at $5 \%$ significance. Seeds kept at $30^{\circ} \mathrm{C}$ had higher water absorption velocity, peaking $27.85 \%$ humidity degree during the change from phase I to phase II. When seeds were subjected to $25^{\circ} \mathrm{C}$, phase I lasted $60 \mathrm{~h}$, peaking $28.35 \%$ humidity degree. Under $20 / 30^{\circ} \mathrm{C}$, such phase lasted $72 \mathrm{~h}$, peaking $28.33 \%$ humidity degree. The temperature $30^{\circ} \mathrm{C}$ led to the highest imbibition velocity but not to a higher germination percentage (phase III), which was detected in seeds kept at $20 / 30^{\circ} \mathrm{C}$.
\end{abstract}

Index terms: Annonaceae; "araticum-de-terra-fria"; imbibition.

\footnotetext{
${ }^{1}$ (Trabalho 028-10). Recebido em: 13-01-2010. Aceito para publicação em: 12-08-2010. Parte da dissertação de mestrado da primeira autora. Auxílio financeiro: CAPES.

${ }^{2}$ M.Sc.,Dept ${ }^{\circ}$. de Botânica, Instituto de Biociências, FCA/UNESP, C.P. 510, CEP 18618-000, Botucatu-SP. E-mail: pnepomuceno@hotmail.com ${ }^{3}$ Eng $^{\text {a }}$. Agra ${ }^{\mathrm{a}}$., CATI, NPMSBS, São Bento do Sapucaí-SP.

${ }^{4}$ Prof'. Dra., Dept ${ }^{\circ}$. de Botânica, Instituto de Biociências, FCA/UNESP, C. P. 510, CEP 18618-000, Botucatu-SP. E-mail: gisela@ibb.unesp.br
} 


\section{INTRODUÇÃO}

No Brasil, a família Annonaceae está representada por 26 gêneros e aproximadamente 260 espécies, desempenhando importante papel na composição da vegetação (MAAS et al., 2001). Espécies comerciais como atemoia, fruta-do-conde e graviola apresentam consumo crescente, porém com oferta interna insuficiente, uma vez que a produção nacional ainda não se apresenta consolidada (MELLO et al., 2003).

Para garantir pomares produtivos, a forma de propagação mais indicada para as anonáceas comerciais é a enxertia. Dentre as diversas espécies que vêm sendo utilizadas como porta-enxerto, citam-se a Annona. reticulata L., A. glabra L. e A. squamosa L. para fruta-do-conde (A.squamosa L.); A. emarginata, $A$. reticulata L., A. montana, $A$. glabra L. e $A$. cherimola Mill. x A. squamosa L. para atemoia ( $A$. cherimola x A. squamosa L.); A. montana, A. emarginata e $A$. squamosa L. para cherimoia (A.cherimola) e $A$. reticulata L., A. montana e $A$. glabra L. para graviola (A. muricata) (BEZERRA; LEDERMAN, 1997; MANICA, 2003).

Segundo Campbell e Phillips (1994), a fruta-do-conde, quando utilizada como porta-enxerto, gera plantas compactas, ideais para a condução comercial, porém Kavati (2004) relata que essa espécie apresenta suscetibilidade a Phytophthora nicotianae var. parasítica e Pythium, responsáveis pela podridão de raízes e colo. Para atemoia, devido às dificuldades na identificação de espécies para porta-enxerto que sejam compatíveis e resistentes, utiliza-se a própria atemoia, mesmo apresentando suscetibilidade a patógenos de solo (STENZEL et al., 2003; KAVATI, 2004).

Com o intuito de sanar dificuldades fitossanitárias, uma alternativa é o emprego do araticum-deterra-fria (Annona emarginata (Schltdl.) H. Rainer) como porta-enxerto (TOKUNAGA, 2000). Dentre as vantagens para seu uso, pode-se citar a tolerância às podridões de raízes, à broca-do-tronco (Cratosomus bombina), compatibilidade de enxertia com a atemoia e a cherimoia, além de induzir maior vigor à copa e resistência tanto a solos secos como encharcados (TOKUNAGA, 2000; SCALOPPI JUNIOR, 2007).

Apesar das vantagens no emprego do araticum-de-terra-fria, existem problemas com a formação do porta-enxerto relacionados com a baixa porcentagem e desuniformidade na germinação, além da rápida redução da viabilidade após a secagem das sementes, não permitindo armazenamento, conforme observações de campo. Outro aspecto a ser considerado são as informações de Smet et al. (1999), refe- rindo-se às citações de Hayat (1963), Sanewsk (1991) e Gaswppd (1995), que afirmam que as sementes de anonáceas apresentam embrião rudimentar, de desenvolvimento lento, que na maioria dos casos não está totalmente diferenciado, mesmo quando os frutos se encontram maduros, o que prejudica a germinação de sementes. Considerando, portanto, a importância da utilização do araticum-de-terra-fria como porta-enxerto para espécies comerciais de anonáceas, estudos relacionados à germinação de sementes desta espécie servirão de subsídio para a melhoria do processo de produção do porta-enxerto.

Segundo Borghetti (2004), a germinação é um processo composto por três fases que consistem na embebição (fase I), na ativação dos processos metabólicos requeridos para o crescimento do embrião (fase II) e na iniciação do crescimento do embrião (fase III). A duração de cada fase depende de propriedades inerentes à semente, como a permeabilidade do tegumento e o tamanho da semente e, também, das condições durante a embebição, como temperatura e composição do substrato (CARVALHO; NAKAGAWA, 2000), sendo que a temperatura influencia na velocidade de absorção de água, na germinabilidade, na velocidade e na uniformidade de germinação e nas reações bioquímicas que determinam todo o processo (CARVALHO; NAKAGAWA, 2000).

Deste modo, o objetivo deste trabalho foi avaliar a influência de diferentes temperaturas nas fases da germinação de sementes de Annona emarginata (Schltdl.) H. Rainer.

\section{MATERIAL E MÉTODOS}

O experimento foi realizado no Laboratório de Fisiologia da Germinação e Dormência de Sementes do Departamento de Botânica, Instituto de Biociências - UNESP, Câmpus de Botucatu-SP.

A extração das sementes dos frutos de araticum-de-terra-fria (Annona emarginata (Schltdl.) H. Rainer) foi realizada manualmente, despolpandose os frutos sob água corrente até a completa remoção da polpa. Para minimizar contaminações, as sementes foram imersas em solução de hipoclorito de sódio a 10\% (i.a.) durante 3 minutos e, em seguida, lavadas com água destilada e deixadas sobre papel-filtro em bancada de laboratório, com temperatura ambiente de $25^{\circ} \mathrm{C}\left(+/-3^{\circ} \mathrm{C}\right)$ durante sete dias para secagem superficial. Após esse período, foi determinado o grau de umidade das sementes, em cinco repetições de 25 sementes, pelo método da estufa a $105^{\circ} \mathrm{C} \pm 3^{\circ} \mathrm{C}$ por 24 horas, conforme Brasil (1992).

Determinado o grau de umidade inicial do lote de sementes, foram realizados dois experimentos: um 
para determinar as fases I e II da germinação e outro para avaliar a fase III nas diferentes temperaturas.

Para as fases I e II, o delineamento experimental foi o inteiramente casualizado, composto de 3 tratamentos (temperaturas: $25^{\circ} \mathrm{C}, 30^{\circ} \mathrm{C}$ e $20 / 30^{\circ} \mathrm{C}$ ), com cinco repetições de 25 sementes por parcela.

As sementes foram pesadas em balança analítica (precisão de $0,001 \mathrm{~g}$ ), acondicionadas em caixas de germinação ('gerbox') de plástico transparente de $11 \times 11 \times 3,5 \mathrm{~cm}$, entre duas folhas de papel mata-borrão umedecido com água destilada (2,5 vezes o peso do papel) e mantidas em câmaras de germinação tipo BOD, nas temperaturas constantes de $25^{\circ} \mathrm{C}$ e $30^{\circ} \mathrm{C}$ e em temperatura alternada de $20-30{ }^{\circ} \mathrm{C}(8-16 \mathrm{~h}$, respectivamente), com luz contínua. Decorrido o período de 1 hora, as sementes foram retiradas dos 'gerbox' e pesadas, tomando-se o cuidado de retirar, antes da pesagem, o excesso de água presente na superfície das sementes, com o auxílio de papel-toalha seco e colocadas novamente nas caixas de germinação.

Este procedimento foi repetido até a estabilização do peso das sementes, em intervalos de 1 hora, durante as primeiras 12 horas, em seguida intervalos de 12 horas até 132 horas e, posteriormente, intervalos de 24 horas até a estabilização do peso.

Os resultados foram apresentados em porcentagem de água presente nas sementes (grau de umidade) em relação à massa da matéria seca inicial.

A variação do grau de umidade (y) ao longo do tempo $(\mathrm{x})$ foi estudada através da regressão não linear monomolecular, com equação $\mathrm{y}=a[1-b \exp$ $(-c \mathrm{x})]$. Obtidas as estimativas dos parâmetros $a, b$ e $c$ para cada unidade experimental, foram verificados os respectivos coeficientes de assimetria. A seguir, os parâmetros das funções foram comparados conforme os tratamentos, ajustados, submetidos à análise de variância e teste de Tukey, a 5\% de probabilidade (CARVALHO, 1996).

Para o estudo da fase III, o delineamento experimental foi inteiramente casualizado, contendo três tratamentos (temperaturas: constantes de $25^{\circ} \mathrm{C}$ e $30^{\circ} \mathrm{C}$ e alternada de $20 / 30^{\circ} \mathrm{C}, 8-16 \mathrm{~h}$, respectivamente), com cinco repetições de 25 sementes por parcela.

A contagem do número de sementes germinadas foi realizada diariamente durante 102 dias. Foram consideradas germinadas as sementes que apresentaram raiz primária com aproximadamente 2 mm de comprimento, segundo Hadas (1976). Foram calculadas a porcentagem e a velocidade média de germinação (LABOURIAU, 1983; SILVA; NAKAGAWA, 1995).

Os dados foram submetidos à análise de variância, e as médias, comparadas pelo teste Tukey, a $5 \%$ de probabilidade. Para os dados de porcentagem de germinação, foram ajustadas curvas de regressão para cada temperatura. Para os dados da porcentagem de germinação final e velocidade média da germinação, foi utilizada a transformação raiz de $(\mathrm{x}+0,05)$, porém os dados apresentados são originais (não transformados) para melhor entendimento (GOMES, 2000).

\section{RESULTADOS E DISCUSSÃO}

Na Figura 1, observa-se que a espécie apresenta as fases I e II bem definidas, independentemente da temperatura, com maior velocidade de embebição nas primeiras horas (fase I) e tendência à estabilidade na fase II, conforme proposto por Bewley e Black (1994).

Verifica-se, na Tabela 1, onde estão apresentados os valores das estimativas dos parâmetros $a, b$ e $c$ da função de Brody, que não houve diferença entre os tratamentos para o parâmetro $a$ (assíntota da função). Isto indica que, nessas temperaturas, as sementes atingem os mesmos teores de água na embebição (fase I da germinação), uma vez que $a$ representa o limite do crescimento de y (teor de água) quando $\mathrm{x}$ cresce indefinidamente. A assíntota da função encontra-se entre 27,85 e 28,35\% de grau de umidade, o que está de acordo com citação de Carvalho e Nakagawa (2000) de que, ao atingir teores de água entre 25 e $30 \%$, sementes endospermáticas iniciam a fase II da germinação.

O parâmetro $b$ apresenta pouco significado biológico e, portanto, não será discutido. Porém, para o parâmetro $c$, que se refere ao valor relacionado à velocidade de variação de $y$, os tratamentos proporcionaram diferenças significativas. Isso significa que a variação da temperatura alterou a velocidade da embebição (Tabela 1). Este resultado confirma citação de Labouriau (1983) e Nóbrega e Rodrigues (1995), de que a velocidade de embebição de água é influenciada quando há modificação das condições de ambiente, mas a quantidade máxima de água adquirida não se altera, pois é uma propriedade dos coloides hidrofílicos da semente, condicionada pela maturação e/ou pelo armazenamento.

$\mathrm{O}$ fato de as sementes mantidas a $30^{\circ} \mathrm{C}$ apresentarem maiores valores para velocidade de embebição de água, é devido à elevação da temperatura provocar redução na viscosidade e aumento na energia cinética da água, aumentando a velocidade da aquisição da água e do metabolismo (MARCOS FILHO, 2005).

Em geral, a fase I é rápida devido ao baixo potencial matricial da semente seca, sendo um processo físico que depende somente da ligação 
da água à matriz da semente. Isso ocorre em qualquer material, morto ou vivo, que contém sítios de ligação ou de afinidade pela água (BORGHETTI, 2004). Embora Marcos Filho (2005) também relate que a fase I é rápida e apresenta duração entre oito e dezesseis horas, e Carvalho e Nakagawa (2000) relatem que esta fase pode completar-se em uma ou duas horas: neste trabalho, a fase I teve duração entre 60 e 72 horas, dependendo da temperatura, e pode ser considerada fase lenta, segundo a literatura, ou rápida, quando se observa todo o processo germinativo para esta espécie.

O tempo elevado de embebição (Fase I) é característico da família Annonaceae, conforme relatado por diversos autores. Ferreira et al. (1997) observaram que, com 12 horas após o início do contato com substrato úmido, as sementes de atemoia continuam embebendo água de modo crescente, demonstrando estar na fase I, enquanto as de fruta-doconde, com 5 horas, a fase I já havia sido concluída. Posteriormente, Ferreira et al. (2006) verificaram que as sementes de atemoia apresentaram ponto de mudança entre as fases I e II após 27 horas de embebição e início da fase III após 234 horas.

Ainda em relação aos diferentes tempos obtidos para a fase I, Richart et al. (2003) concluíram que ocorre a transição da fase I para a fase II nas sementes de atemoia aproximadamente entre $30 \mathrm{e}$ 36 horas após o início da embebição. Melo (2005) observou que, em sementes de $A$. crassiflora, somente após 7 dias de embebição as mesmas entraram na fase II da germinação.

Com o exposto, constatou-se, portanto, que as sementes de araticum-de-terra-fria apresentam permeabilidade à água, que as fases I e II da aquisição de água são bem definidas, conforme Bewley e Black (1994), porém a quantidade de água adquirida em cada momento é desuniforme, conforme se verifica na Figura 2 (a e b). Observa-se que não houve ajuste matemático dos dados devido ao comportamento irregular da quantidade de água adquirida pelas sementes, apresentando flutuações durante o período de embebição.

A aquisição de água inicia-se logo na primeira hora de contato das sementes com o substrato úmido (Figura 2a). Porém, após aproximadamente 24 horas, ocorreu outro aumento na quantidade de água adquirida, o que se repetiu com 60 horas nas sementes submetidas a $25^{\circ} \mathrm{C}$ e 72 horas com sementes submetidas a $30 / 20^{\circ} \mathrm{C} \mathrm{e} 30^{\circ} \mathrm{C}$ (Figura $2 \mathrm{~b}$ ) e coincidiu com o início da fase II da germinação (Figura 1).

Verifica-se, portanto, que embora a fase I (Figura 1) tenha sido bem definida, a aquisição de água em cada momento não ocorre de modo uniforme (Figura 2a e b). Isto demonstra que, a partir de determinado teor de água, já há ativação do processo metabólico e aumento de substâncias com função osmótica, que reduziram o potencial hídrico da semente, o que resultou em vários aumentos de aquisição de água no final da fase I. Estas observações são confirmadas por Carvalho e Nakagawa (2000), principalmente porque, a partir de 14-16\% de água na semente, há acentuado aumento na intensidade respiratória e, portanto, aumento de substâncias osmoticamente ativas, demonstrando que esta fase não é totalmente dependente só da variação do potencial matricial da semente, mas também da variação do potencial osmótico.

Neste contexto, na fase II, há uma continuação dos processos metabólicos ativados no final da fase I, como a síntese e duplicação de DNA, degradação de reservas e alongamento das células da radícula (BEWLEY; BLACK,1994; BORGUETTI, 2004), cujas alterações são internas e, portanto, não são visíveis. Nesta fase, só haverá aquisição de água caso a variação do potencial osmótico seja suficiente para alterar o gradiente de potencial hídrico entre a semente e o substrato, o que resulta em pequenos aumentos no teor de água da semente.

A fase III da germinação é caracterizada pela protrusão da raiz primária, que foi observada no segundo experimento, aos 88 dias $(2.112 \mathrm{~h}$ ), quando se usou a temperatura de $25^{\circ} \mathrm{C}$, aos 32 dias $(768 \mathrm{~h})$, com $30^{\circ} \mathrm{C}$ e aos 14 dias $\left(336 \mathrm{~h}\right.$ ) com $20 / 30^{\circ} \mathrm{C}$ (Figura 3 ).

Embora $30^{\circ} \mathrm{C}$ tenha promovido maior velocidade de embebição (Tabela 1), não refletiu em maior porcentagem de germinação, o que foi verificado com a alternância de temperatura $\left(20 / 30^{\circ} \mathrm{C}\right)$, que promoveu os maiores valores de porcentagem e velocidade média de germinação (Tabela 2 e Figura 3), o que, segundo Copeland e McDonald (1999), é possível, uma vez que temperaturas alternadas interferem no balanço inibidor/promotor, promovendo a germinação. Cabe acrescentar que a alternância de temperatura também favoreceu a germinação de sementes de outras anonáceas, conforme observado por Ferreira et al. (2002), com atemoia cv. Thompson, e por Zucareli et al. (2007), com sementes de A. squamosa L., o que reforça as observações dos autores. 
TABELA 1 - Valores das estimativas dos parâmetros $a, b$ e $c$ da função de Brody das curvas de embebição de sementes de Annona emarginata (Schltdl.) H. Rainer (araticum-de-terra-fria) submetidas a diferentes temperaturas.

\begin{tabular}{cccc}
\hline Tratamento & $a$ & $b$ & $c$ \\
\hline $25^{\circ} \mathrm{C}$ & $28,35 \mathrm{~A}^{1}$ & 0,1606 & $0,0266 \mathrm{AB}$ \\
$30^{\circ} \mathrm{C}$ & $27,85 \mathrm{~A}$ & 0,1544 & $0,0323 \mathrm{~A}$ \\
$20 / 30^{\circ} \mathrm{C}$ & $28,33 \mathrm{~A}$ & 0,1782 & $0,0244 \mathrm{~B}$ \\
\hline $\mathrm{CV}(\%)$ & 1,62 & - & 11,54 \\
\hline
\end{tabular}

Função monomolecular estimada: $\mathrm{y}=\mathrm{a}[1-\mathrm{b} \exp (-\mathrm{c} \mathrm{x})]$

${ }^{1}$ Médias seguidas de mesma letra, na coluna, não diferem significativamente entre si, pelo teste Tukey, ao nível de 5\% de probabilidade.

TABELA 2 - Porcentagem total de germinação e velocidade média de germinação (VMG) de sementes de Annona emarginata (Schltdl.) H. Rainer (araticum-de-terra-fria) submetidas a diferentes temperaturas.

\begin{tabular}{cccc}
\hline Tratamento & \% Germinação & VMG \\
\hline $25^{\circ} \mathrm{C}$ & $2,0 \quad \mathrm{~B}^{1}$ & $0,0057 \mathrm{C}$ \\
$30^{\circ} \mathrm{C}$ & $8,5 \mathrm{~B}$ & $0,0193 \mathrm{~B}$ \\
$20 / 30^{\circ} \mathrm{C}$ & $27,0 \mathrm{~A}$ & $0,0340 \mathrm{~A}$ \\
\hline $\mathrm{CV}(\%)$ & 29,37 & 4,15 \\
\hline
\end{tabular}

${ }^{1}$ Médias seguidas de mesma letra, na coluna, não diferem significativamente entre si, pelo teste Tukey, ao nível de $5 \%$ de probabilidade.

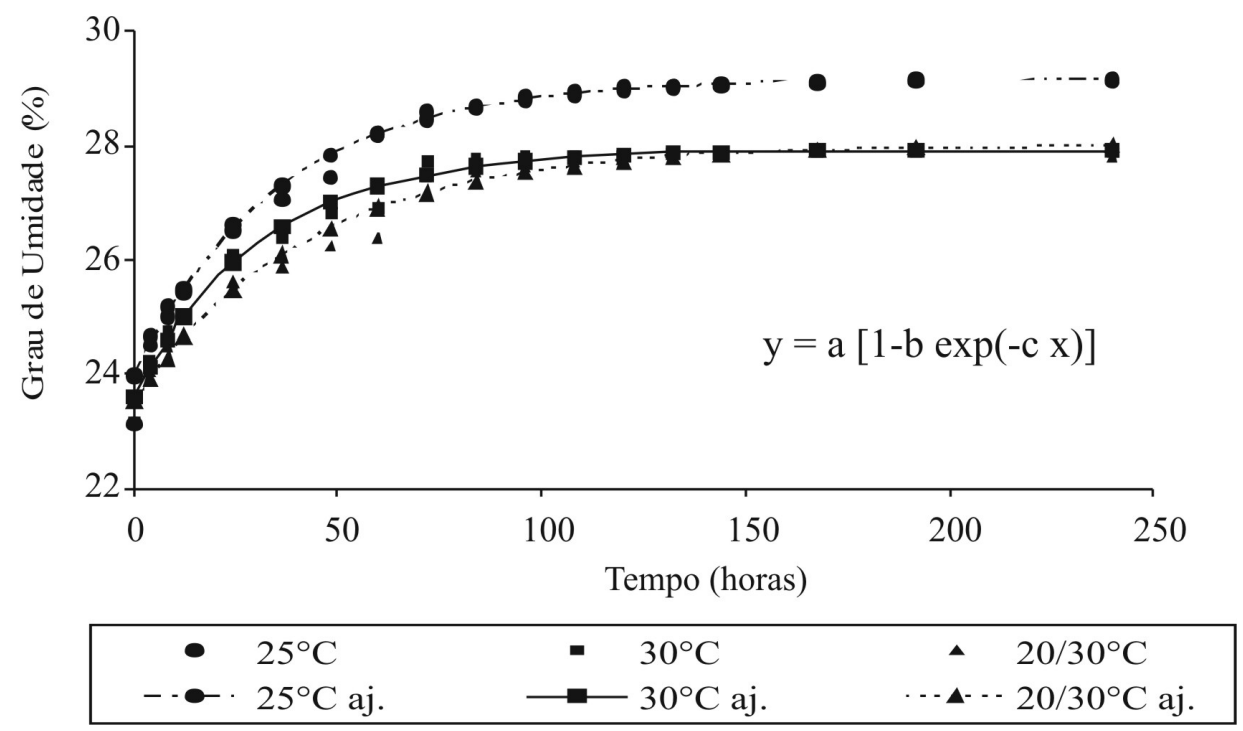

FIGURA 1 - Fases I e II da germinação de sementes de Annona emarginata (Schltdl.) H. Rainer (araticumde-terra-fria), submetidas a diferentes temperaturas, em função do grau de umidade e do período de embebição. 
(a)

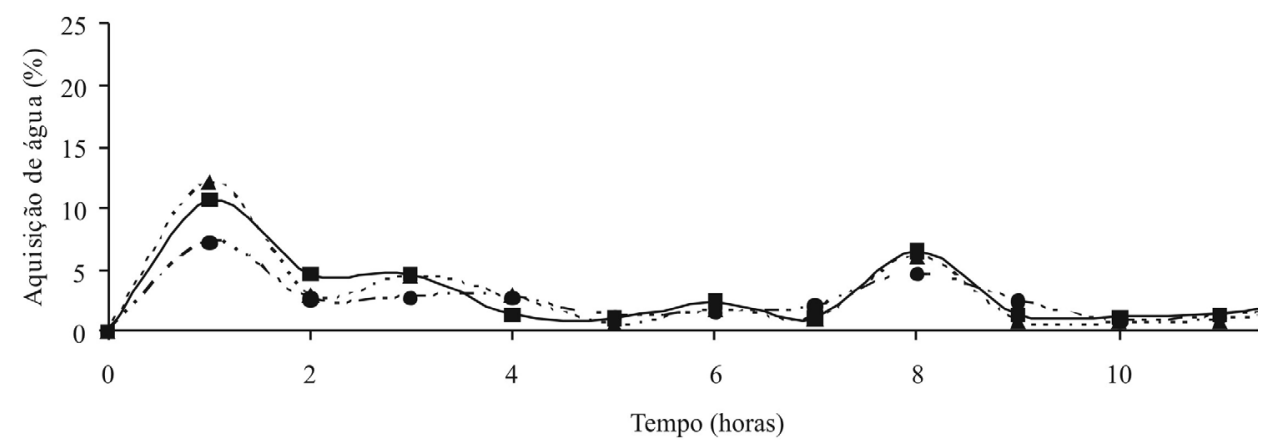

- - $-25^{\circ} \mathrm{C} \longrightarrow 30^{\circ} \mathrm{C} \cdots \mathbf{A}^{-\cdots} 20 / 30^{\circ} \mathrm{C}$

(b)

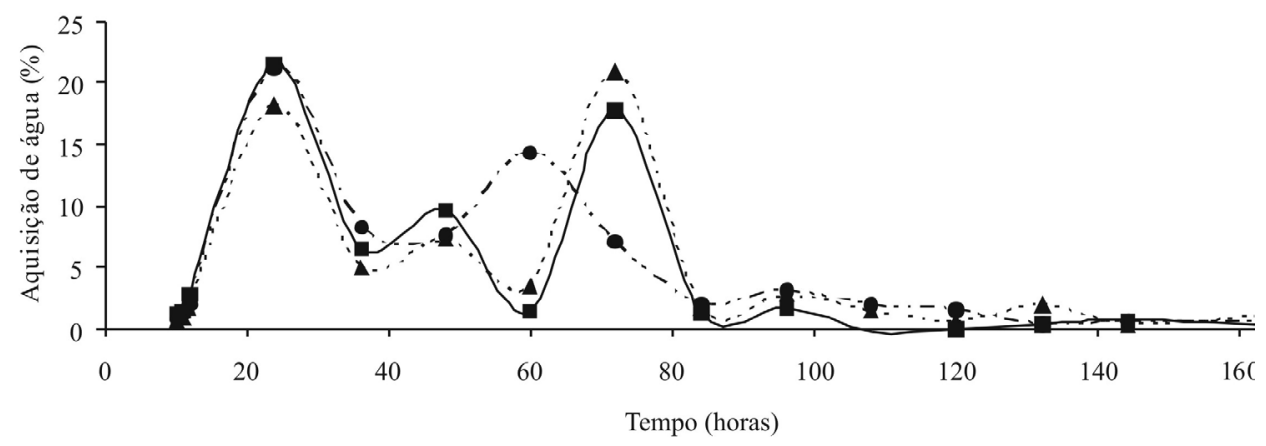

$-\cdot \bullet \cdot 25^{\circ} \mathrm{C} \longrightarrow 30^{\circ} \mathrm{C} \cdots \backsim \cdot \cdots 20 / 30^{\circ} \mathrm{C}$

FIGURA 2 - Quantidade de água adquirida pelas sementes de Annona emarginata (Schltdl.) H. Rainer (araticum-de-terra-fria), em cada momento de avaliação em diferentes temperaturas, até 12 horas após o início do experimento (a) e de 12 a 168 horas (b). 


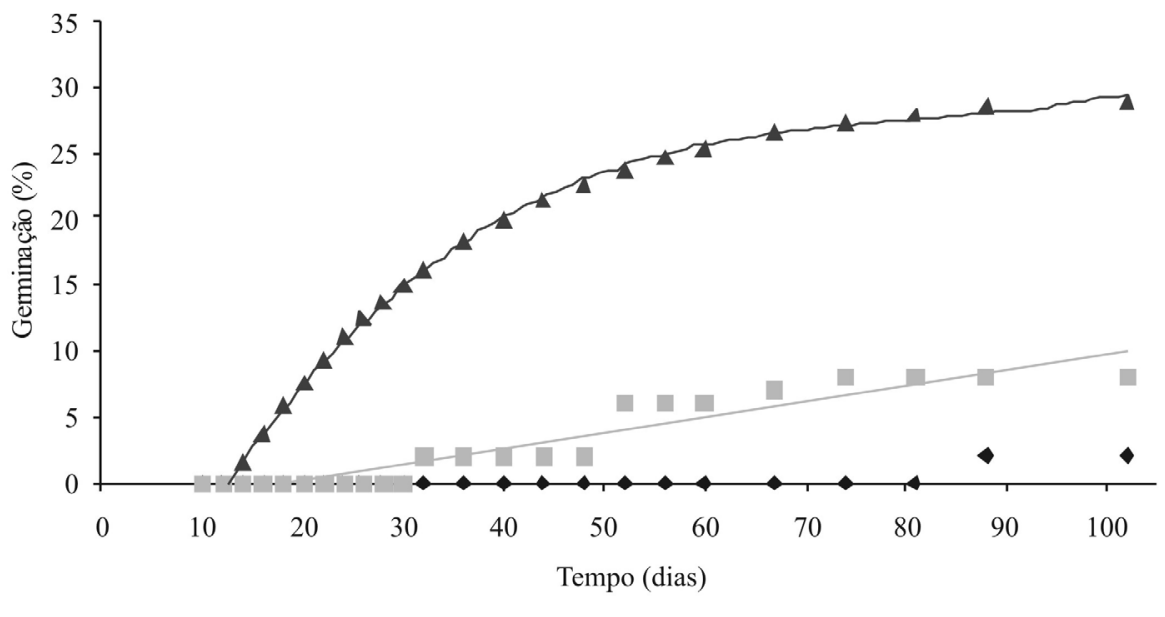

- $25^{\circ} \mathrm{C} \quad-30^{\circ} \mathrm{C} \quad \Delta 20 / 30^{\circ} \mathrm{C}$

$30{ }^{\circ} \mathrm{C} \quad \mathrm{y}=0,1195 \mathrm{x}-2,1858 \quad \mathrm{R} 2^{2}=0,8963$

$20 / 30{ }^{\circ} \mathrm{C} \quad \mathrm{y}=29,8758[1-1,6681 \exp (-0,0403 \mathrm{x})]$

FIGURA 3 - Germinação de sementes de Annona emarginata (Schltdl.) H. Rainer (araticum-de-terra-fria) submetidas a diferentes temperaturas.

\section{CONCLUSÃO}

Em sementes de araticum-de-terra-fria, a mudança da fase I para a fase II da germinação só ocorre quando determinado teor de água é alcançado (entre $27,85 \%$ e $28,35 \%$ ), enquanto a germinação visível (fase III) é favorecida pela alternância de temperatura $\left(20 / 30^{\circ} \mathrm{C}\right)$.

\section{AGRADECIMENTOS}

Os autores agradecem ao Prof. Dr. Renato de Silva Mello, pela identificação da espécie, à $\operatorname{Prof}^{a} \mathrm{Dr}^{\mathrm{a}}$ Marta Maria Mischan, pela orientação estatística, e à CAPES, pelo auxílio financeiro concedido.

\section{REFERÊNCIAS}

BEWLEY, J.D.; BLACK, M. Seeds: physiology of development and germination. $2^{\text {nd }}$ ed. New York: Plenum Press, 1994. 445p.

BEZERRA, J.E.F.; LEDERMAN, I.E. Propagação vegetativa de anonáceas por enxertia. In: SÃO JOSÉ, A.R.; SOUZA, I.V.B.; MORAIS, O.M.; REBOUÇAS, T.N.H. Anonáceas, produção e mercado (pinha, graviola, atemoia e cherimólia). Vitória da Conquista: DFZ/UESB, 1997. p. $61-67$.
BORGHETTI, F. Dormência embrionária. In: FERREIRA, A.G.; BORGHETTI, F. (Org.). Germinação: do básico ao aplicado. Porto Alegre: Artimed, 2004, p.109-123.

BRASIL. Ministério da Agricultura e Reforma Agrária. Regras para análise de sementes. Brasília: SNDA/DNDV/CLAV, 1992. 365p.

CAMPBELL, C.W.; PHILLIPS, R.L. The atemoya. Gainesville: University of Florida, 1994.

CARVALHO, L.R. de. Métodos para comparação de curvas de crescimento. 1996. $172 \mathrm{f}$. Tese (Doutorado) - Faculdade de Ciências Agrárias e Veterinárias, Universidade Estadual Paulista, Jaboticabal, 1996.

CARVALHO, N.M.; NAKAGAWA, J. Sementes: ciência, tecnologia e produção. 4.ed. Jaboticabal: FUNEP, 2000. 588p.

COPELAND, L.D.; McDONALD, M.B. Principles of seed science and technology. New York: Chapman \& Hall, 1999. 409p.

FERREIRA, G.; GUIMARÃES, V.F.; PINHO, S.Z.; OLIVEIRA, M.C.; RICHART, A.; BRAGA, J.F.; DIAS, G.B. Curva de absorção de água em sementes de atemoia (Annona cherimola MILL. x Annona squamosa L.) CV. 'Gefner'. Revista Brasileira de Fruticultura, Jaboticabal, v.28, n.1, p.121-124. 2006. 
FERREIRA, G.; CEREDA, E.; SILVA, C.P.; CUNHA, R.J.P.; CATANEO, A. Imbibition study of sugar apple (Annona squamosa L.) and atemoya (Annona squamosa L. X A. cherimola Mill.) sedes. In: CONGRESSO INTERNACIONAL DEANONÁCEAS, 1., 1997, México. Memorias... Chapingo: Universidad Autônoma Chapingo, 1997. p.210-224.

FERREIRA, G.; RODRIGUES, J.D.; DIAS, G.B.; DETONI; A.M.; TESSAR, S.M. Semillas de atemoya (Annona cherimola Mill x Annona squamosa L.) cv. 'Thompson' sometidas a temperaturas y concentraciones de ácido giberélico. In: CONGRESSO INTERNACIONAL DE ANONÁCEAS, 2000. Chile. Memorias... Quillota: Universidade Católica de Val Paraíso, 2002. p.16.

GOMES, P. F. Curso de estatística experimental. 14.ed. Piracicaba: Nobel, 2000. 477p.

HADAS, A. Water uptake and germination of leguminous seeds under changing external water potential in osmotic solution. Journal of Experimental Botany, Oxford, n.52, p.480-489, 1976.

KAVATI, R.O. O Cultivo de anonáceas no Estado de São Paulo. In: ENCONTRO DE ANONÁCEAS: Geração de Emprego e Renda, 2004, Botucatu. Anais... Botucatu: FCA, UNESP, 2004. p.39-70.

LABORIAU, L. G. A. Germinação das sementes. Washington: Secretaria Geral da Organização dos Estados Americanos, 1983. 171p.

MAAS, P.J.M.; KAMER, H.M.; JUNIKKA, L.; SILVA, R.M.; RAINER, H. Annonnaceae from Central-eastern Brazil. Rodriguésia, Rio de Janeiro, v. 52, n. 80, p. $65-98,2001$.

MANICA, I. Frutas Anonáceas: ata ou pinha, atemólia, cherimóia e graviola. Tecnologia de produção, pós-colheita e mercado. Porto Alegre: Cinco Continentes, 2003. 596p.

MARCOS FILHO, J. Fisiologia de sementes de plantas cultivadas. Piracicaba: Fealq, 2005. 495p.

MELLO, N.T.C. de; NOGUEIRA, E.A.; MAIA, M.L. Atemóia: perspectivas para a produção paulista. Informações Econômicas, São Paulo, v.38, n.9, p.7-13, 2003.
MELO, D.L.B. Dormência em sementes de Annona crassiflora Mart. 2005. 51f. Dissertação (Mestrado - Manejo Ambiental) - Universidade Federal de Lavras, Lavras, 2005.

NOBREGA, L.H.P.; RODRIGUES, T.J.P. Efeitos do estresse hídrico sobre a absorção de água durante a germinação de sementes e o estabelecimento de plântulas de soja. Informativo ABRATES, Londrina, v.5, n.1, p.51-8, 1995 .

RICHARD. A.; OLIVEIRA, M.C.; FERREIRA, G. GUIARÃES, V.F.; DIAS, G.B. Avaliação de métodos para determinação da curva de embebição de sementes de atemoia (Annona cherimola Mill x Annona squamosa L.). In: CONGRESSO BRASILEIRO DE FISIOLOGIA VEGETAL, 9., 2003, Atibaia. Resumos... Atibaia: Sociedade Brasileira de Fisiologia Vegetal, 2003. p.215.

SCALOPPI JUNIOR, E.J. Propagação de espécies de Annonaceae com estacas caulinares. 2007. $92 \mathrm{f}$. Tese (Doutorado em Produção Vegetal) - Faculdade de Ciências Agrárias e Veterinárias, Universidade Estadual Paulista, Jaboticabal, 2007.

SILVA, J.B.; NAKAGAWA, J. Estudo de fórmulas para o cálculo da velocidade de germinação. Informativo ABRATES, Londrina, v.5, n.1, p.62-73, abr. 1995.

SMET, S. DE; DAMME, P. VAN; SCHELDEMAN, $\mathrm{X}$.; ROMERO, J. Seed structure and germination of cherimoya (Annona cherimola Mill.). Acta Horticulturae, Wageningen, n.497, p.269-278, 1999.

STENZEL, N.M.C.; MURATA, I.M.; NEVES, C.S.V.J. Superação da dormência em sementes de atemoia e fruta-do-conde. Revista Brasileira de Fruticultura, Jaboticabal, v.25, n.2, p. 305-308, 2003.

TOKUNAGA, T. A cultura da atemoia. Campinas: CATI, 2000. 80p. (Boletim Técnico, 233)

ZUCARELI, V.; FERREIRA, G.; SILVÉRIO, E.R.V.; AMARO, A.C.E. Luz e temperatura na germinação de sementes de Annona squamosa L. Revista Brasileira de Biociências, Porto Alegre, v.5, supl.2, p.840-842, 2007. 